\title{
Automated Promotion Machine: Emerging IS for the Retail Industry in China
}

\author{
Yan Chen', Jun Tian ${ }^{1}$ and Xiangzhen Kong ${ }^{2}$ \\ 'School of Management, Xi'an Jiaotong University, Xi'an 710049, P.R. China \\ chenyan02@gmail.com, tianjun@mail.xjtu.edu.cn \\ ${ }^{2}$ U-SYS Consulting \& Information Technology Co., Ltd, Guangzhou 510630, P.R. China \\ jennykong@u-sys.com.cn
}

\begin{abstract}
Technical developments in information technologies coupled with business interests to improve promotion productivity, are spurring research in the area of information systems for sales promotion in retail industry, which facilitate promotion analysis and automate promotion implementation. Auto Promotion Machine (APM), presented in this paper, can perform promotion analysis based on consumer personal or household characteristics, history consumer purchasing information, and tracking data of consumer shopping process; carry out promotion implementation through interacting with consumer by in-store promotion terminal or online Internet terminal. Potential impacts of APM on retail industry are discussed form the perspectives of manufacturers, retail stores, and consumers, respectively. Two levels of APM are described, representing varying degrees of automation and intelligence. Some applications of APM in today's business practice are showed according to the two levels. Finally, important topics in need of further study are identified, and can be followed by other researchers; thus, accelerate the cumulating of knowledge in using information technology to support sales promotion in retail industry.
\end{abstract}

Keywords: EIS for service sector, Business intelligence, Marketing and campaign management

\section{INTRODUCTION}

Rapidly changing economic environments and constantly shifting consumer preferences, lead to increasingly market uncertainty. [1]Companies respond to this situation by emphasizing on their marketing function and using information technology to support marketing activities. [2]The idea of using IT to support marketing may trace back to Kotler [3] when he proposed creating an organization unit to provide instantaneous high-quality information and analytical assistances to marketing. From then on, academics and practitioners have contributed a large quantity of literalities on information systems in marketing. Traditionally, IS (e.g. Marketing Information Systems) has been seen as a device to facilitate decisionmaking in marketing management [4]. Nowadays, leading marketing consulting and information systems providers in China, such as U-SYS, are developing and supplying machines which can automatically perform promotion activities in retail stores in China. However, we can hardly see academic research on such automated

Please use the following format when citing this chapter

Chen, Y., Tian, J., Kong, X., 2007, in IFIP International Federation for Information Processing, Volume 255, Research and Practical Issues of Enterprise Information Systems II Volume 2, eds. L. Xu, Tjoa A., Chaudhry S. (Boston: Springer), pp. 1261-1270. 
information systems in the Chinese context. And one purpose of the paper is to define some key terms and accelerate researches in this emerging field in China.

This paper is organized as follows: Section 2 defines the term Automated Promotion Machine (APM) to describe systems like those provided by U-SYS and analyze how APM influences manufacturers, retailer, and consumers. Section 3 identifies two levels of Automated Promotion Machine. Section 4 proposes some important issues that are in need of further investigation.

\section{EMERGING PROMOTION AUTOMATION}

Sales promotions can be directed at either consumers or channels. Sales promotions targeted at the consumer are called consumer promotions, while those aimed at channels are called trade promotions [5]. Consumer promotions, which are used by manufactures or retailers to increase sales to consumers, are the focus of this paper.

\section{I Automated Promotion Machine: Definition}

This paper proposes a new term Automated Promotion Machine (APM) to cover emerging sales promotion automations for the retail industry in China. APM is defined as follows:

Automated Promotion Machine (APM): APM automatically conduct promotions by interacting with consumers. Consumers access to APM through either in-store machines or online portals. Based on historical buying records, consumer characteristics, and shopping process tracking, APM customizes sales promotions to individuals via in-store machine, Internet, or mobile devices. The most special feature of APM is its promotion automation.

\subsection{Manufacture's Perspective}

Kotler [6] pointed out that trade promotion continues to be the largest single spending category in the marketing mix budget of U.S. packaged goods companies. How about it in China? Besides budgets, Silva-Risso et al. [7] maintained that Negotiations between manufacturer and retailers of the sales promotion calendar are common events in the consumer packaged goods industry. And they intended to develop decision support systems to help address this issue. In addition, Blattberg et al. [8] generalized that that retailers often do not pass $100 \%$ trade deals on to consumers. By employing Automated Promotion Machine, manufactures can promote their products or services directly to targeted consumers and may lower their dependences on trade promotion to some extent.

On the other hand, when conducting sales promotions by promotions staffs, some agency costs may incur. Zhou [9] analyzed potential problems in free sample promotions, and pointed out that promotion staffs may arbitrarily give out samples to untargeted consumers. Worse still, some staffs may retain some samples for their own 
purposes. Hence, they argued that the way we gave out free samples should be improved and innovated. Indeed, APM is just such an innovative approach for sales promotion. Compared with traditional way of conducting promotion activities, APM selects target consumers based on consumer profiles, and deliver personalized sales promotion directly by interacting with consumers and enhance the effectiveness and efficiency of sales promotion. Thus we propose the following proposition:

Proposition 1: The relationship between marketing expenditure and marketing performance will be stronger for firms using Automated Promotion Machine than those not.

\subsection{Retailer's Perspective}

Blattberg et al. [8] generalize that "advertised promotions can result in increased store traffic". With Automated Promotion Machine, sales promotions have the potential to reach consumers through many ways, including in-store machine, online portal, and mobile device. The easy accessibility of promotion information may broaden the coverage of promotions and increase store traffics. On the other hand, Gerstner et al. [10] argue that consumers attracted by certain low-priced items under promotion may also buy complementary products with large retail markups while they were in stores. Hence, we present the following proposition:

Proposition 2: The relationship between sales promotion and retailer sales will be stronger for firms using Automated Promotion Machine than those not.

Burke [11] maintained that through modern technology, retailer may pay close attention to consumer's unique needs with a low cost. Automated Promotion Machine, of course, endows with the capability to cater to the uniqueness of consumers. Thus, we bring up the following proposition:

Proposition 3: Automated Promotion Machine will have a positive effect on consumer's store loyalty.

\subsection{Consumer's Perspective}

Databases and data mining techniques may help company determine the right information to consumers, while customers welcome this type of customized promotion. [12] That is, personalized promotion systems allow customers to take advantage of customized sales promotions. [13] Automated Promotion Machine (APM) tailors personal recommendations based on databases. Hence, APM may creates value for consumer through reducing consumer' information searching costs, saving product searching time, and reducing expenditure. We propose the following proposition: 
Proposition 4: Customized promotion information sent by Automated Promotion Machine will have a positive effect on consumer's satisfaction.

\subsection{Systems' Perspective}

The renowned Chinese economist Professor Wu [14] hold that production costs of Chinese companies is pretty low, while transaction costs are rather high. Transaction costs may be significantly lowered by adopting supply chain management based on information infrastructure. As for the retailing industry, Reardon et al. [15] maintained that information technology contributes to retailers' productivities; however, they also provide evidences that retailers are underutilizing information technology.

As for manufacturers, Li et al. [16] conducted longitudinal surveys of Fortune 500 companies and found that many of these firms were indeed using information to support their marketing plans. Importantly still, they found that marketer were becoming frequent user of computer, and actively participated in creating specific application for their own needs. However, Venter [17] showed that marketing decision-makers are generally dissatisfied with information systems in South African service organizations. And Venter argued that it may because the disconnectedness between IT and marketing department; and because they just generate information but not add value to information. By the same token, Tian et al. [18] claimed that the underdevelopment of marketing information systems in China may due to the unsatisfactory integration of marketing research and information systems research in China. Thus, we present the following proposition:

Proposition 5: The relationship between the deployments of Automated Promotion Machine and their performance in the supply chain will be stronger for those with better cooperation between IS function and marketing function.

\section{AUTOMATED PROMOTION MACHINE: TWO LEVELS}

Automated Promotion Machines are classified into two levels according to their differences in automation and intelligence. Level 1 APM, to which most real world systems in China belong, use historical buying records and consumer characteristics to customize personalized sales promotions for consumers by interacting with them via in-store systems or online portals. Level 2 APM, which is the advanced version of Level 1 APM, can track consumer buying process and can be accessed by wireless devices.

It should be noted that these two levels just represent technical advancement. The determinant of which one is better is the alignment of IT and business. According to Kearns et al. [19], the degree that IT planning represents business plans determines the competitive advantages of the firm to a large extent. By the same token, Jing [20] maintained that technology was just a tool to support business; and argue that companies should select the most appropriate technologies rather than the most advanced ones when designing their systems. 


\subsection{Automated Promotion Machine: Level 1}

Level 1 APM combine promotion analytical capabilities and automated promotion implementation features. It performs this two functions based historical records and consumer characteristics (no tracking data).

The analytical jobs are preformed based on data mining techniques. Rygielski et al. [21] identified several applications of data mining techniques in the retail industry, including basket analyzing, sales forecasting, database marketing, and merchandise planning. The promotion automation features require in-store and/or online portal to interact with consumer.

Two systems provided by two leading Chinese marketing information systems vendors are belong to Level 1 APM. They are: Zhierxing systems [22] by Guangzhou Taisi Management Science and Technology Co., Ltd; and Youhuiduo systems [23] by U-SYS Consulting \& Information Technology Co., Ltd.

Zhierxing target marketing systems customize coupons, advertising and valueadded information to consumer offered by manufacturers or retailers to consumers based on in-store scanner data in POS. As illustrated in Figure 1, promotions, which can be redeemed in specified store during certain time period, together with store receipts are given to consumer by cashier.

Figure 2 illustrates what the in-store terminal of Youhuiduo systems looks like. As mentioned above, the most unique feature of Youhuiduo systems is its automation. The in-store terminal can automatically distribute promotions (e.g. trial samples and coupons) to consumers; and automatically receive and redeem them.

A controversial feature of the Youhuiduo systems is that it does not connect with POS of retail store. It obtains consumer's buying records by scanning printed receipts and uses optical character recognition (OCR) technology to recover these data into Youhuiduo's database. Based on the database, it analyzes consumer preference and automatically conducts promotions.

Zhierxing systems gains competitive edges through information sharing between its providers and retailers. Switching costs are created when retailers make specific investment to Zhierxing systems. According to Clemons [24], the IT-based switching costs may be source of sustained competitive advantage. On the other hand, retailers will usually be aware of the risk of being locked in and captured by IT suppliers if they make specific investments; hence they may try to neutralize these threats by requiring guarantees or by seeking alternative IT suppliers[25].

Besides the separation between Youhuiduo systems and retailer's POS, it automatically performs sales promotions without any participation of cashiers. When receiving in-store printed receipts from cashiers, consumers freely choose whether to use Youhuiduo. This may be some kind of price discrimination. Based on consumer heterogeneity, the ill-informed, high transaction cost, or impatient customers are charged higher prices [10]. 


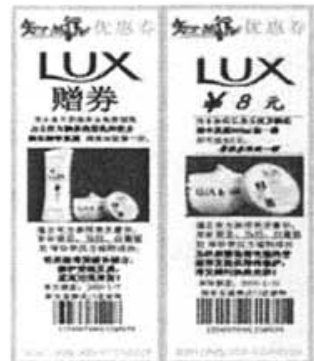

(A)

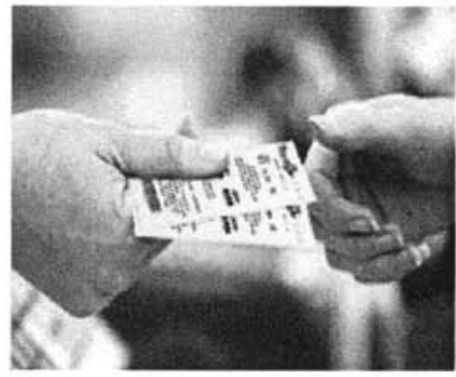

(B)

Figure 1. (A) Coupons and Free Sample Voucher by Zhierxing Systems (B) Coupons and Free Sample Voucher Hand over to Consumers by Cashiers in Retail Stores
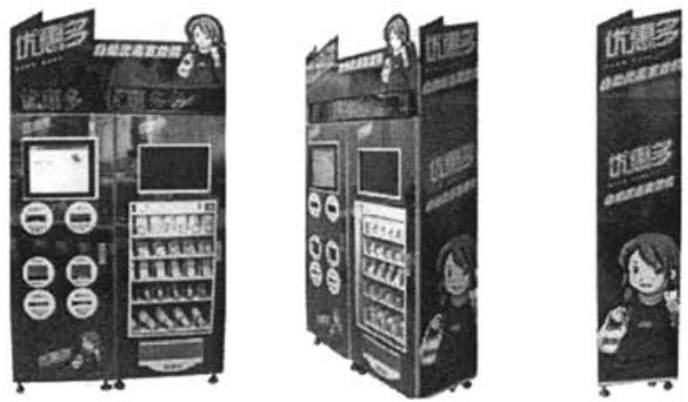

Figure 2. The In-store Terminal of Youhuiduo Systems

\subsection{Automated Promotion Machine: Level 2}

Level 2 APM is more advanced in technology that Level 1 APM. Level 2 APM records tracking data of consumer shopping process; and provide multi-channel access, including in-store systems, online portals, and mobile device. How to track consumer shopping process in an ethical way is still a concern. In terms of technology, Burke [11] argued that there are detailed records of website usage behavior in the online environment; while in the offline retail stores, recently developed technology, such as RFID, GPS, and video-based customer tracking solutions, can be applied to collect and analyze these tracking data.

These consumer shopping process data, together with personal characteristics and purchasing basket information, can be used to support analytical jobs and automatic promotion implementation. Moreover, based on tracking information, the location of consumers may be positioned. Thus, when consumer work through certain product 
category, APM may push dedicated promotion information onto interactive terminals around that category and attract consumer to sales promotion.

There is no real-world application of Level 2 APM in the retail industry in China. However, we wonder, will it be the future direction of Level 1 systems like Zhierxing and Youhuiduo?

\section{FUTURE RESEARCH ISSUES}

In this section, we propose major research issues related to Automated Promotion Machine. What we intend to show are just some general research topics, not a complete list of all questions relevant to Automated Promotion Machine.

\subsection{The Design of Automated Promotion Machine}

Great efforts are needed related to hardware and software configurations of Auto Promotion Machine. Since most researchers and practitioners are building systems form the ground up, their systems represent significantly varying beliefs in using information technology to support the promotion function. These different beliefs have led to varying systems configurations. It is time for us to sum up the experiences from early researches and developments of APM. In particular, important driving factors of APM should be identified for different driving factors may require different configuration of APM.

\subsection{Value of Automated Promotion Machine}

Lee et al. [26] point out "bullwhip effect" which distorts information along the supply chain. Cachon et al. [27] analyzed the value of information sharing and estimated positive business value gains associated with it. Because manufactures can directly obtain consumer demands form Automated Promotion Machine, it may contribute to reducing the "bullwhip effect" and creating value for the supply chain. Thus, we propose the following proposition:

Proposition 6: Automated Promotion Machine has a positive effect in reducing the "bullwhip effect" along supply chain.

\subsection{Business Model of Automated Promotion Machine}

A good business model should answers the two fundamental questions [28]: How do APM make money? What is the underlying economic logic that explains how APM can deliver value at an appropriate cost?

APM brings together the manufacture, the retailer, and consumers. Which party is responsible for running APM? Should it be the manufacture, the retailer, or a third party provider? Zhierxing systems and Youhuiduo systems are all run by third party 
provider. Is this the best practice? Or is this just one of many alternatives? If a third party comes to run APM, then, there will be four parties in APM. What factors determine the success of balancing benefits of the four parties and achieve business successes?

\subsection{Automated Promotion Machine and Shopping Science}

Underhill [29] argued that the Science of Shopping, based on observational and ethnographic research, was concerned with providing information to improve retailers' competitive edges and lower their possibilities of making wrong decisions. As Burke [11] claimed, computer-based tracking devices provide efficient and reliable means to collect and analyze data on consumer shopping process.

The database of Automated Promotion Machine should consist of data form three aspects: consumer characteristics, historical purchasing records, and computer tracking of consumers shopping process. More researches are needed to figure out how we can use this database to support the research of the Science of Shopping and provide insights for retailers to make better decisions.

\section{CONCLUSIONS}

Auto Promotion Machine has the potential to significantly enhance the productivity of promotion activities in retailing industry. APM allows manufacturers and retailers to perform promotions more efficiently and effectively, thus, reduce promotion costs. Meanwhile, because promotions can be customized to cater to the need of individual consumer, consumers can also share some benefits from applying APM. By employing appropriate information technology to support promotion functions, supplies and demands of promotions can be better matched, thus, all parties in the systems may share some benefits, some of which have been pointed out in Section 2 of this paper. After providing potential values of APM, we identify two different levels of APM that can address such values; and point out some issues that are in needed for further research. If the work of individual investigators is conducted follows this path, cumulative knowledge on using information technology to support promotions in retail industry can emerge.

\section{ACKNOWLEDGMENTS}

This project was partially supported by the Open Fund of the Key Laboratory of Information Management and Information Economics, Ministry of Education of China (No.F0607-25) and the National Natural Science Foundation of China (No.70372049). 


\section{REFERENCES}

1. J.S. Raju and A. Roy, Market Information and Firm Performance, Management Science. Volume 46, Number 8, pp.1075-1084, (2000).

2. M. Colgate, Marketing and Marketing Information System Sophistication in Retail Banking, Service Industries Journal. Volume 20, Number 1, pp.139-152, (2000).

3. P. Kotler, A Design for the Firm's Marketing Nerve Center, Business Horizons. Volume 9, pp.63-74, (1966).

4. J.M. Talvinen, Information Systems in Marketing, European Journal of Marketing. Volume 29, Numver 1, pp.8-26, (1995).

5. K. Gedenk, S.A. Neslin, and K.L. Ailawadi, Sales Promotion, in Retailing in the 21st Century, eds. M.K. Mantrala and M. Krafft (Springer: Berlin, 2005), pp.345-359.

6. P. Kotler, Marketing Management: Analysis, Planning, Implementation, and Control (Prentice-Hall: NJ, 1997).

7. J.M. Silva-Risso, R.E. Bucklin, and D.E. Morrison, A Decision Support System for Planning Manufacturer's Sales Promotion Calendar, Marketing Science. Volume 18, Number 3, pp.274-300, (1999).

8. R.C. Blattberg, R. Briesch, and E.J. Fox, How Promotions Work, Marketing Science. Volume 14, Number 3, pp.122-132, (1995).

9. L. Zhou and P. Zhou, Analysis of Potential Problems in Sample Promotion, Market Modernization. Number 7, pp.196-197, (2006).

10. E. Gerstner and J.D. Hess, A Theory of Channel Price Promotions, The American Economic Review. Volume 81, Number 4, pp.872-886, (1991).

11. R.R. Burke, The Third Wave of Marketing Intelligence, in Retailing in the 21st Century, eds. M.K. Mantrala and M. Krafft (Springer: Berlin, 2005), pp.113-125.

12. J. Wind and A. Rangaswamy, Customerization: The Second Revolution in Mass Customization, Journal of Interactive Marketing. Volume 15, Number 1, pp.13-32, (2001).

13. M. Fujita and R.P. Murotani, Systems and Methods for Personalized Product Promotion, FreePatentsOnline (2006). http://www. freepatentsonline.com/20060277103.html (Accessed July 9, 2007).

14. J. Wu, Improving the Competent Ability of Chinese Circulation Industry Through Implementing Supply Chain Management, China Business and Market. Number 10, pp.4$6,(2003)$.

15. J. Reardon, R. Hasty, and B. Coe, The Effect of Information Technology on Productivity in Retailing, Journal of Retailing. Volume 72, Number 4, pp.445-461, (1996).

16. E.Y. Li, R. McLeod, and J.C. Rogers, Marketing Information Systems in Fortune 500 Companies: A Longitudinal Analysis of 1980, 1990, and 2000, Information and Management. Volume 38, Number 5, pp.307-322, (2001).

17. P. Venter, Developing a Marketing Information Systems (MKIS) Model for South African Service Organizations. Ph.D Thesis, University of South Africa (2000).

18. D. Tian and J. Ma, Advances in Marketing Decision Support System, Chinese Journal of Management Science. Volume 12, pp.672-677, (2004).

19. G.S. Kearns and A.L. Lederer, A Resource-Based View of Strategic IT Alignment: How Knowledge Sharing Creates Competitive Advantage, Decision Sciences. Volume 34, Number 1, pp.1-30, (2003).

20. L. Jing, Using Information Technology to Transform Circulation Enterprises (in Chinese), Commercial Research. Number 14, pp.31-35, (2004).

21. C. Rygielski, J.C. Wang, and D.C. Yen, Data Mining Techniques for Customer Relationship Management, Technology in Society. Volume 24, Number 4, pp.483-502, (2002). 
22. Anonymous, Introduction to the Systems, Guangzhou Taisi Management Science and Technology Co., Ltd. (2005) http://www.325.com.cn/cn/system_1.html (Accessed July 9, 2007).

23. Anonymous, Introduction to Youhuiduo, U-SYS Consulting \& Information Technology Co.,Ltd. (2007) http://www.retailinnovation.com.cn/xitongjieshao.html (Accessed July 9, 2007).

24. E.K. Clemons, Information Systems for Sustainable Competitive Advantage, Information and Management. Volume 11, Number 3, pp.131-136, (1986).

25. F.J. Mata, W.L. Fuerst, and J.B. Barney, Information Technology and Sustained Competitive Advantage: A Resource-Based Analysis, MS Quarterly. Volume 19, Number 4, pp.487-505, (1995).

26. H. Lee, V. Padmanabhan, and S. Whang, Information Distortion in a Supply Chain: The Bullwhip Effect, Management Science. Volume 43, Number 4, pp.546-558, (1997).

27. G.P. Cachon and M. Fisher, Supply Chain Inventory Management and the Value of Shared Information, Management Science. Volume 46, Number 8, pp.1032-1048, (2000).

28. J. Magretta, Why Business Models Matter, Harvard Business Review. Number 5, pp.8692, (2002).

29. P. Underhill, Why We Buy: The Science of Shopping (Simon and Schuster: New York, 1999). 